Educational accountability and students with a disability in Australia

Ian Dempsey and Robert Conway

Running head:

Educational accountability for students with a disability

Keywords: disabilities, special education, testing problems, accountability.

Address for correspondence:

Ian Dempsey

Centre for Special Education and Disability Studies

University of Newcastle

Callaghan NSW 2308

Tel. 0249216282

Fax 0249216939

Email ian.dempsey@newcastle.edu.au 
Educational accountability and students with a disability in Australia

One of the outcomes of regular education reform in Australia has been the development of a national testing program for school students. This paper examines the degree to which students with a disability participate in this testing, and the extent to which the testing of students with a disability may help to achieve the National Goals of Schooling in this country. Several international comparisons with the Australian situation are made. A number of recommendations are made to facilitate the participation of students with a disability in national testing as a means of achieving the goal of educational equity for these students. 


\section{Educational reform and educational accountability}

The last thirty years has seen the level of educational accountability increase significantly (Elliot, Hyeonsook, Thurlow \& Ysseldyke, 1995; Jones, 1999; Labon, 1999; National Centre for Educational Statistics [NCES], 2000; Quenemoen, Lehr, Thurlow \& Massanari, 2001). An outcome of this change has been the development of national and international standards for the education of all students, incorporating the measurement of educational outcomes. The philosophy underpinning the development of such standards is that all students from all backgrounds should have the same opportunities to learn and to achieve (Labon, 1999; Thomas \& Bainbridge, 2001).

Measurement of educational outcomes is considered important on several levels. At the international level, it permits the comparison of educational outcomes across countries (Jones, 1999). Curriculum and teaching strategies may similarly be compared, leading to information about common issues and standards in education. This, it is argued, plays a part in ensuring the economic competitiveness of countries in a globalised marketplace by informing national and international policy makers about the knowledge and skills of their human resource base (NCES, 2000). The measurement of educational outcomes at the national level forms an essential part of accountability systems (Quenemoen et al., 2001; Sirotnik \& Kimball, 1999). These systems may drive education reform by informing policy makers about the effectiveness of current practices in education, including teaching strategies, resource management and curriculum development (Falk, 2002; Roach, Salisbury \& McGregor, 2002).

National education reform in Australia has been influenced by both the Hobart and the Adelaide Declarations (Department of Education Science and Training [DEST], 2002a; Forlin \& Forlin, 1998; Pascoe, 2001). The Hobart Declaration was the outcome of the Education Ministers meeting in Hobart in 1987 and laid the foundation for the recognition of a common set of outcomes for learning. These became recognised as Key Learning Areas and laid the foundation for assessment and curriculum development across the states (see Department of Education, Training and Employment, South Australia [DETE SA], 2002; Forlin \& Forlin, 1998). In 1999, the Education Ministers met again, and endorsed a set of nationally agreed, common 
goals for schooling to "establish a foundation for action among State and Territory governments” (DEST, 2002b p1). The purposes for establishing such goals were to improve educational partnerships, increase the quality of teaching and the curriculum, and "increase public confidence in school education through explicit and defensible standards that guide improvement in students' levels of educational achievement” (DEST, 2002b p2). These were endorsed as the Adelaide Declaration on National Goals for schooling in the twenty-first century and were framed in inclusive language.

An early practical implementation of these goals was the establishment of the National Literacy and Numeracy Plan (DEST, 2002c). This plan was built on the relevant National Goals and consisted, firstly, of national numeracy and literacy benchmarks, or "minimum acceptable standards for literacy and numeracy at a particular year level” (DEST, 2002d p1). These benchmarks were considered relevant to all students "while recognising that a very small percentage of students suffer from severe disabilities and so may be unable to achieve the minimum standards" (DEST, 2002d p2). The second aspect of the Plan was the development of a program of assessment and reporting against those benchmarks to ensure accountability in the achievement of the national goals (DEST, 2002c). Finally, a professional development plan for educators was established to support them in the implementation of this plan (DEST, 2002c).

Despite good intentions, the movement for increased educational accountability has been accompanied by a number of unintended consequences (Albrecht \& Joles, 2003; Quenemoen et al., 2001). These have been well documented in the U.S., where the focus of educational reform has moved towards a business-influenced accountability system (Boscardin, 1997; McNeil, 2000; Skrtic, 1995). A number of critics have suggested that standards-based reform and other accountability systems may threaten quality and equality in education through:

1. encouraging teachers to teach to a test, abandoning more authentic and creative curriculum content and presentation (Dorn, 1998; McNeil, 2000);

2. de-skilling teachers as the training requirements for teaching become closely allied to the accountability systems (Falk, 2002); and, 
3. contradicting the philosophy of equal opportunity. That is, those students who do not learn the same way as most other students, or do not have the same literacy skills or cultural knowledge as the tests require, may be distinctly disadvantaged (Albrecht \& Joles, 2003; Popham, 1999). The groups most disadvantaged are children from minority cultures, children of low socio-economic status and children with disabilities.

\section{International comparisons of national educational outcomes reporting}

International comparative studies of educational outcomes were introduced in the early 1960s by the International Association for the Evaluation of Educational Achievement (IEA). In an attempt to monitor and compare the efficacy of national education systems, a number of international comparative studies were introduced (Jones, 1999), and have covered areas such as mathematics, science, reading and civics. One of the most comprehensive of these studies was developed by the International Association for the Evaluation of Educational Achievement (IEA), in the early 1980s (Elliot et al., 1995; Jones, 1999; NCES, 2000).

Currently there are three major international comparative studies of the educational outcomes of school students being conducted on a cyclical basis. These are the Trends in Mathematics and Science Study (TIMSS), the Progress in International Reading Literacy Study (PIRLS), and the Programme for International Student Assessment (PISA). PISA assesses reading, mathematical and scientific literacy. TIMSS and PIRLS are conducted by the IEA, and PISA is conducted by the Organisation for Economic Cooperation and Development (OECD).

There is very little information about students with disabilities and their participation in, or exclusion from, these international studies (Elliot et al., 1995). The sampling manual for the TIMSS and the International Assessment of Educational Progress (IAEP), included general guidelines for the participation of students with disabilities. The guidelines for both these studies state that all children should be given the opportunity to participate where possible. However, students identified in these guidelines as educable mentally retarded, functionally disabled or non-native 
language speakers (Elliot et al., 1995), may be exempted from participating at the discretion of the participating school's executive staff.

The OECD’s Technical Report for PISA 2000 provides for the exclusion of students on the basis that they are educable mentally retarded, functionally disabled or nonnative speakers. While the Technical Report notes that PISA is designed to be as inclusive as possible, the extent to which students with a disability complete the PISA is unclear (OECD, 2002). Indeed, the general participation rate of the most recently reported PISA varies widely across countries (OECD, 2002). Participation ranges from $100 \%$ in North Korea, to $82 \%$ in the U.K., $70 \%$ in the U.S., and $55 \%$ in the Netherlands.

The exemption of students with disabilities from large-scale, international studies of education has been sparsely discussed, despite changing definitions of disability and increasingly inclusive educational philosophies. The exclusion of students with disabilities from testing is motivated by, what Vanderwood, McGrew and Ysseldyke (1998) refer to as, “altruistic motivations” (p366). That is, it is intended to protect students from the emotional distress of participating in tasks that require abilities, skills and knowledge the students do not possess (Albrecht \& Joles, 2003).

Guidelines based on this motivation often require principals or special educators to make a judgement as to who may or may not be able to participate in a manner that will give a true indication of their learning and abilities (Elliot et al., 1995). However, there are likely to be a number of other reasons for the exclusion of students with a disability from large scale testing.

Examples of these reasons are:

1. The achievement of educational excellence. Where test scores are used to compare the educational performance of countries or schools, it becomes important to produce the best score possible. Hence the motivation to exclude portions of the population that may negatively influence that score, including students with disabilities (Dorn, 1998). 
2. The devolution of responsibility. How educational success and failure is conceptualised will influence the inclusion of students with disabilities in testing. Jurisdictions that interpret disability as a function of educational provisions may be more willing to be inclusive in order that the total education system may be held accountable for students’ learning. However, jurisdictions that perceive disability as a condition solely within the child may be more likely to exclude students with disabilities to ensure the education system is not held accountable for the students’ deficiencies (Dorn, 1998).

3. Gatekeepers' roles. Personnel such as principals, planning and support teams, district and regional committees, and parents often act as gatekeepers in determining who will and won't be included in testing. In the absence of formal policies, it is their beliefs about the purpose and consequences of tests and assessments that will ultimately determine who will participate (Dorn, 1998; Dyson, 1997; Mitchell \& Kugelmass, 1997).

Although the literature often focuses on the role of the principal, school and the education jurisdiction in terms of exclusion of students from testing, parents and caregivers have a critical role to play in any consideration of their child being included or not in educational testing.

It is apparent that the sampling procedures of international studies as well as the educational philosophy of jurisdictions may influence the participation of students in large-scale testing, especially the participation of students with disabilities. However, the link between inclusive education philosophies and other contextual factors, study sampling procedures and countries' participation rates can only be implied from the data collected since, as mentioned previously, information available about the participation of students with disabilities is vague at best. This is in stark contrast to the range of reports on the influence of age (see O’Leary, 2000; NCES, 2000), gender, socio-economic status, culture (see Bechger, Schooten, Glopper \& Hox, 1998; OECD, 2002) or geographical location (see Webster \& Fisher, 2000), may have on educational test performance. Another factor that may be significantly contributing to this contrast is the absence of a consistent definition of disability across national and 
international educational settings (Dyson, 1997; Labon, 1999; Mitchell \& Klugelmass, 1997). Issues of definition of disability are explored later in this paper.

Mitchell and Klugelmass (1997) note that "the degree of isomorphism between policy, legislation and practice varies from country to country” (p1). This observation is particularly evident in the U.S. and Australia where educational policy and practice differs from state to state (Boscardin, 1997; Brown, 1997). Booth and Ainscow (1998) expand on this thought, suggesting that "particular cultures and national policies ... permit a plurality of perspectives, including challenges to an official view” (p8). These authors suggest that one main factor influencing the match between policy and practice is the type of control, or accountability measures, sustained to monitor practice. These measures are now discussed as they relate to several Western countries.

\section{United Kingdom}

In the UK, practice is monitored nationally through the national assessment system which is linked closely to the National Curriculum (NC) (Firestone \& Mayrowetz, 2000). The NC was introduced in an effort to ensure that all students were provided with the same curricula and learning experiences regardless of their abilities or disabilities (Dyson, 1997; Labon, 1999; Lingard, 2000).

Despite the strong inclusive intent of the NC, the curriculum contains a clause that allows the permanent or temporary "disapplication" or modification of the NC and assessment for students whose "circumstances or conduct means that they cannot participate fully in the NC” (Dyson, 1997; Zammit, et al., 1999, p.19).

"Disapplication" is determined by the Local Education Authority, parents, teachers and specialist staff, according to the mandated process of a statement of special education needs. This process as well as other special education practices, and the overall outcomes for students with disabilities, are monitored through the Code of Practice (DfEE, 1994 as seen in Stakes and Hornby, 2000), and regular inspections (Stakes \& Hornby, 2000).

In the U.K., acknowledgment that students with special educational needs may not be able to achieve the standards set in the NC appears in the form of exemptions. For 
example, the Qualifications and Curriculum Authority (as cited in Zammit et al., 1999), state that all students must be assessed with the exception of the "few children unable to take part" due to "exceptional circumstances" (p.19). For these students the NC may be modified or disapplied. Wedell (1997) and Zammit et al. (1999) report that these "disapplications" may be temporary, such as for students new to the school system or experiencing emotional problems. Alternatively, for students with special education needs, longer-term modifications or disapplications may apply. The process to achieve long term modifications or disapplications for students is mandated under Section 364 of the 1996 Education Act and must be agreed upon by the Local education authority in consultation with parents, teachers and specialist staff. Wedell (1997) reports that attempts to formulate downwards extensions of the curriculum and more flexible assessment strategies have yet to be satisfactorily developed.

\section{United States of America}

A focus of education reform in the U.S. in the past two decades has been "statistical accountability” (Dorn, 1998; Vanderwood, et al 1998). That is, testing and reporting on educational outcomes using aggregated scores have increasingly been the focus of accountability systems in the U.S. during this period. In the U.S., each state has its own accountability system (Giacobbe, Livers, Thayer-Smith, \& Walther-Thomas, 2001). In 1997, assessment and reporting on outcomes for students with disabilities was mandated in amendments made to IDEA as a result of concerns about the exclusion of these students from accountability systems (Consortium on Inclusive Schooling Practices [CISP], 1998; Nolet \& McLaughlin, 2000; Vanderwood et al., 1998). The only exemptions from testing are made for those for whom participation would invalidate the assessment due to the nature of the student's disability. In reporting, exceptions may also be made for students for whom reporting would reveal their identity (Massanari, 2002; Ysseldyke \& Nelson, 1998).

In 1990, the National Centre on Education Outcomes (NCEO) was established to cooperate with state departments of education to "facilitate the development and use of indicators of educational outcomes for students with disabilities” (Ahearn, 2000 p1). Since that time NCEO (see Ahearn, 2000; Quenemoen et al., 2001), and others (e.g. Giacobbe et al., 2001), found that a significant proportion of students with disabilities were excluded from assessment processes for many reasons. These reasons 
were mainly based on the irrelevance of the content and structure of the assessment tools for students with disabilities, and the political, social or economic consequences attached to the results of the assessments (Albrecht \& Joles, 2003; Dorn, 1998; Vanderwood et al., 1998).

At about the same time as the NCEO was established, the 'New Standards Project' was introduced. Hoff (2001) explains that:

“Organisers of the New Standards Project envisioned a curriculum built around standards ... They promised to create tests to measure students' skills, not just their knowledge of facts. And they expected that teachers would centre everything they did on the new curriculum and preparation of students to take the tests. The founders said they'd have the pieces in place by 2001.” (Hoff, 2001 p1).

In short, the New Standards Project was about introducing standards and curriculumbased assessment and accountability systems into U.S. schools. However, the goals of this project remain largely unmet (Hoff, 2001; Pascoe, 2001). The curriculum and assessment tools developed by New Standards have been adopted by only small pockets of schools across several states in the U.S. The project has achieved more widespread influence over the philosophical underpinning of state assessment systems. However, Hoff (2001) and Pascoe (2001) report that this influence has largely resulted in the inadequate adoption of some items of New Standards curriculum and assessment tools into existing, and often poorly aligned assessment and accountability systems.

\section{Australia}

In the late 1980s there was a movement towards the development of an Australian national curriculum framework or 'profiles', similar to that developed in the U.K. (Lokan, 1997; Pascoe, 2001). A change in Federal Government in 1994 saw this national agenda abandoned and placed into the hands of state and territory governments, hence the monitoring of student outcomes continues to be largely the responsibility of state and territory education departments (Lokan, 1997; Pascoe, 2001; Zammit, et al., 1999). However, in April 1999 the State, Territory and 
Commonwealth Ministers for Education endorsed a set of national goals, supported by a National Literacy and Numeracy Plan (DEST 2002b). The national goals formed part of the Adelaide Declaration (1999 as cited in DEST, 2002b), the predecessor of which was the Hobart Declaration (Forlin \& Forlin, 1998). These declarations have established a national framework for what is known as the Key Learning areas, a concept on which the states and territories have built their curricula, syllabuses and assessment processes (see DETE SA, 2002; Forlin \& Forlin, 1998).

The national goals of education include the following:

1. "In terms of curriculum, students should have ... attained the skills of numeracy and English literacy; such that, every student should be numerate, able to read, write, spell and communicate at an appropriate level.

2. “Schooling should be socially just, so that ... students' outcomes from schooling are free from the effects of negative forms of discrimination based on sex, language, culture and ethnicity, religion or disability.” (DEST, 2002c, p.3).

The outcomes from the National Literacy and Numeracy Plan were:

1. The establishment of minimum standards or benchmarks for literacy and numeracy.

2. All states and territories conduct literacy and numeracy tests annually for students in Years 3, 5 and, from 2001, Year 7.

3. The results of these tests are reported annually in the National Report on Schooling in Australia (see Ministerial Council for Education, Employment, Training and Youth Affairs [MCEETYA], 2002; DEST, 2002d).

Each state or territory education department is responsible for its own test format and administration (Bruniges, 2001; Zammit et al., 1999). Similarly, Zammit et al. (1999) report that each state and territory is responsible for setting the guidelines for the inclusion or exclusion of students with disabilities in these assessment programs. The 
result is that the inclusion of students with disabilities in the testing process varies significantly across the country. The 2000 National Report on Schooling notes that the percentage of students exempted from testing ranged from .6\% in Tasmania to 3.7\% in the Northern Territory (MCEETYA, 2002). However, for the Northern Territory these figures included a high percentage of indigenous students and students with a language background other than English.

Students with disabilities are often excluded from reporting in Australia. The 2000 National Report on Schooling in Australia reported disaggregated data according to student gender, status as an indigenous student or student with a language background other than English (MCEETYA, 2002). However, there was no disaggregated reporting of data for students with disabilities apart from noting the percentage of students exempted from the assessments. Further, the report notes that "students who are exempt are reported as having not achieved the benchmark" (MCEETYA, 2002, p.7).

At this time, it is impossible to determine the characteristics of students excluded from Australian testing. The most commonly excluded students include students with intellectual disabilities and students with limited proficiency in the English language (ACER, 2002; Giacobbe et al., 2001; Zammit et al., 1999). However, state and territory guidelines often provide for principals or other special education staff to make a judgement about student participation. Consequently, it is likely that there may be significant variations in student participation within states, and within districts and regions within those states (Quenemoen et al., 2001).

\section{Canada}

Education is the responsibility of the individual provinces and territories in Canada. Attempts to establish an accountability system to monitor the educational outcomes of students with disabilities in Canada have encountered difficulties due to the different conceptualisation of disability and special education throughout the country (Dore et al., 1998; Smith \& Foster, 1997). However, in 1993 the Council of Ministers of Education, Canada (CMEC) endorsed the Victoria Declaration (Yackulic \& Noonan, 1998). These authors discuss two fundamental concepts driving this Canada-wide agreement. These include: 
1. That "education identify a full scope of learning as the mandate for schools" (p.5).

2. The concept of “opportunity to learn” (p.13).

The result of this agreement was the establishment of a nationwide program of assessment for mathematics, reading, writing and science called the School Achievement Indicators Program [SAIP] (Council of Ministers of Education, Canada [CEMC], 2002a). Randomly selected 13 and 16 years old students from all provinces and territories participate in the assessments. The pamphlet for parents and students on the 2001 SAIP Writing Assessment III (CMEC, 2002b) states the following: "Special-needs students will be accommodated as they would be in their regular school environment” (p.2). As with the Australian experience, in practice this translates to a wide variation between provinces and territories in the participation and exclusion rates of students with disabilities.

\section{New Zealand}

The New Zealand experience of national assessment illustrates the conflict that often occurs between political and educational agendas (Mitchell, 1997; Winstanley, 2001). New Zealand's education system operates in a way similar to the U.K. That is, New Zealand also has a national curriculum that is monitored by mandated processes and is implemented by local authorities (Mitchell, 1997). The main review of assessment and reporting procedures in New Zealand has been in relation to the implementation of the New Zealand National Certificate of Educational Achievement (NCEA) for students finishing secondary school (Carter et al., 2001; Winstanley, 2001). The conflict has been in the political demand for a standardised score and the desire of the education community to eliminate such scores as they were seen as "a confusing nonsense” in the context of employment and future education (Winstanley, 2001). A compromise between the two agendas resulted in a system which both provides a profile of the student's achievements across the relevant subject areas of the NC, and a standardised grade for that subject (Winstanley, 2001).

All students completing their education in the final three years of secondary schooling are able to participate in the NCEA, which consists of both internal and external 
assessment tasks (Winstanely, 2001). The guidelines for the NCEA in 2002 outline how the specific needs of students with disabilities may be accommodated in the assessment process (NCEA, 2002). Because the NCEA was implemented for the first time in 2002, with students being assessed at level 1 only, not a great deal of information is currently available about the results of NCEA (Carter, et al, 2001).

\section{Changing definitions and placements of students with a disability}

Our conception of disability has been influenced by an ongoing shift from what has been described as the medical model or functionalist view, towards a social construction or interpretivist view of disability (Kalyanpur \& Harry, 1999; Lupart, 1998; Skrtic, 1995). This shift has been associated with a parallel movement in special education practice from segregated settings to more inclusive placements (Lupart, 2000). Changes in the identification and education of students with disabilities have been influenced by political, social and economic contexts (Booth \& Ainscow, 1998). Some factors driving this change are legislation, economic rationalism, lobbying by parents and educators, and educational research.

Traditional definitions of disability have been grounded in scientific and medical knowledge bases that have produced a functionalist view of disability and special education (Skrtic, 1995). From this perspective, disability is defined as a group of categorical conditions able to be objectively and unequivocally identified by specialised professionals. Traditionally, the main disabling conditions were biological impairments such as physical disabilities like blindness and deafness.

From the functionalist point of view, as diagnostic technology improved and public and professional awareness of disability increased, many more categories of disability have been identified (Lupart, 2000; Skrtic, 1995). Recent additions to these categories include speech and language impairments, autism spectrum disorder, learning disorders, and behaviour and emotional disorders. Kalyanpur and Harry (1999) describe some of these newer categories of disability as judgement categories because objectivity in the diagnosis of such disabilities has been questioned. As Hahn and Hegamin (2001) point out, the study of disabilities has now moved from being orientated in scientific and clinical studies to an increasing orientation in social 
science. This has enabled an understanding of the influence contextual factors, such as culture and resources, have on the development and diagnosis of disabilities.

At this time, Australian educational jurisdictions still rely heavily on functionalist definitions of disability, which typically exclude categories of special need such as learning difficulty and behaviour disorder. These functionalist definitions are often closely associated with definitions used to access funding, and to disability categories used to allocate scarce educational resources. In contrast, the definition of disability in the Disability Discrimination Act (DDA) is much broader than those used by Australian educational authorities. The impending release of education standards for the DDA (Nelson, 2003), which will require the jurisdictions to meet minimum standards in educational services for students with a disability, will likely lead to a broadening of the definition of disability in schools.

The past decade has seen a significant increase in the number of students with a disability being identified in school systems, particularly in regular classes. At the same time, there has been a philosophical movement towards more inclusive placements for students with a disability (Foreman, 2001), although, this movement has not necessarily resulted in a significant movement of students with a disability from segregated to inclusive settings (Dempsey, Foreman, \& Jenkinson, 2002). Regardless, the National Goals of Schooling that developed from the Adelaide Declaration in 1999 reflect this movement to inclusiveness and social justice in educational outcomes for students with a disability in Australia.

\section{Including students with a disability in nationally reported assessment}

A philosophy governing the educational reform movement in countries such as Australia, the U.K. and the U.S. is one of equal opportunity. For students with disabilities, this has lead to the movement for more inclusive education and reporting of educational outcomes (Ford, Davern, \& Schnorr, 2001; Labon, 1999). However, in the context of accountability systems, this philosophy and policy has not always been reflected in practice. For example, the requirement that all students complete a standardised assessment tool discriminates against students with disabilities. That is, students who by definition are unable to "meet the same 
educational requirements as their general education peers" are not being treated with equity when asked to perform according to the same standards (Albrecht \& Joles, 2003). Thus, in practice, the philosophy of inclusion becomes a question of equity, or finding ways in which the effects of individual abilities or disabilities may be addressed so that they do not unfairly advantage or disadvantage students in the education system. This is in comparison to the common interpretation of equity as one standard for all (Dorn, 1998; Thomas \& Bainbridge, 2001).

The U.S. experience illustrates this tension. The re-authorisation of IDEA in 1997 required three outcomes. First, that students with disabilities were to be included in general state and district-wide assessment programs with necessary accommodations. Second, that students unable to participate in general state or district-wide assessments were to be provided alternate assessment, for which states were to develop guidelines by July 2000. Finally, schools were to report on the participation and scholastic performance of students with disabilities (Schiller et al., 2002).

Despite these requirements, Giacobbe et al. (2001) reported that by 2001, while twenty-three states indicated that all students would participate in the state assessment plans, the actual participation rates varied significantly due to widely variant guidelines. The highest participation rate was in Kentucky, where less than $2 \%$ of students were excluded from the assessment process. However, very few states include data on children with disabilities in their reporting practices, (Thurlow et al., 2000).

Reasons for exclusions of students with a disability from testing included unspecified determinations by the IEP team, students receiving instruction in self-contained classrooms, parent choice, short-term U.S. residency, and/or limited English skills, and religious reasons (Giacobbe et al., 2001). Only in North Dakota, Washington or Wisconsin did guidelines require that alternative assessment procedures also be described in the student's IEP. As Mitchell and Klugelmass (1997) and Booth and Ainscow (1998) suggest, passing legislation may be a catalyst for change, but it cannot guarantee that the philosophies behind that legislation will be adopted universally. Many factors, including the centre of educational control and the distribution of resources contribute to how these reforms are adopted into practice 
(Quenemoen et al., 2001). In order to ensure that accountability systems match developments in philosophy and policy, it is essential to provide resources and incentives for the relevant education authorities to update their accountability systems (Ford et al., 2001; Matlock et al., 2001). As illustrated previously, the continued focus on narrow standardised assessment procedures does not reflect the inclusive philosophy of equal educational opportunity for all (Albrecht \& Joles, 2003; Dorn, 1998; Ford et al., 2001). A change in the philosophical focus of accountability systems is essential in the achievement of inclusive outcomes.

The focus should be on developing accountability systems that allow all students to be assessed within a common framework while accommodating individual differences. For example, CISP (1998), Ford et al. (2001), Matlock et al. (2001), McLaughlin et al. (1999), Quenemoen et al. (2001) and Sirotnik and Kimball (1999) suggest that the positive outcomes of such as system would include:

1. Educators and policy makers more likely to take responsibility for all students, including students with disabilities.

2. Raising the standard of special education through improved curricular options, higher expectations and improvements in instructional techniques.

3. Achievement of a more holistic and factual representation of educational outcomes for the school population.

4. Educational equity for all students.

Dorn (1998) states that the dilemma of including or excluding students with disabilities from assessments is "rooted in the tension between wanting to protect students with disabilities from the deleterious consequences of high-stakes testing and ... wanting whatever accountability systems exist to pay attention to their interests” (p.24). It must be recognised that education systems cannot be successfully managed by relying solely on a punitive accountability system (CISP, 1998; McNeil, 2000; Sirotnik \& Kimball, 1999). The consequences attached to the data gathered must 
match the substance and purpose of the accountability system (Firestone \& Mayrowetz, 2000; Popham, 1999).

CISP (1998) and Quenemoen et al. (2001) argue that accountability systems will only drive education reform where the consequences provide information to the public, as well as policy makers, as to the current processes, inputs and outcomes of education; and where appropriate professional development and training is provided. In order to adequately manage these consequences, the purpose of the accountability system must be clear (Dorn, 1998; Quenemoen et al., 2001; Ysseldyke \& Nelson, 1998). It must be clear which of the many aspects of education are being measured, and it must be clear whether the focus is on ensuring equity or the provision of an appropriately challenging curriculum, and it must be clear for which audience(s) the data is being gathered. For example, is the focus on providing summative information to the public, or more specific information for the purpose of driving policy reforms in education?

As discussed, a variety of issues may motivate educators to exclude students with disabilities from accountability systems. Exclusion may occur during the development of the assessment tools, during the assessment, or in reporting the assessment results (Elliot \& Thurlow, 1997). In the development of assessment tools, especially standardised measures, failure to include subgroups of the population such as students with disabilities from sampling measures has lead to assessments developed at a level and formatted in such a way as to preclude the participation of students with disabilities (McDermott \& McDermott, 2002). This issue is being addressed by the development of testing accommodations and alternate assessment strategies for those students unable to participate in the general assessment system (see Giacobbe et al., 2001; Quenemoen et al., 2001; NSW Board of Studies, 2002). However, the development of these tools is still new and uniform guidelines for their use do not exist (Giacobbe et al., 2001; Elliot et al., 1997; Kleinert, Haig, Kearns \& Kennedy, 2000; Kearns, Klienert \& Kennedy, 1999). Further, Thurlow and Bolt (2001) state that most accommodations are accompanied by controversy due to the lack of consistent empirical evidence supporting their use. The main concern, in this case, is that accommodations may invalidate assessment results by significantly advantaging or disadvantaging students. 


\section{Conclusion}

There are many factors that may account for inconsistencies in the participation rates in testing of students with disabilities at the Australian school, state and national levels. These inconsistencies may only be overcome if the following issues are addressed. First, a common educational definition of students with disabilities needs to be developed. This is essential both for defining any group to be excluded and to determine the participation rates for students with disabilities. The imminent introduction of education standards to supplement the DDA may facilitate the adoption of a common definition of disability across Australian educational jurisdictions.

A second requirement to reduce inconsistencies in the participation rates of students with a disability is a need to specify allowable reasons for exemption. One possible reason for exemption is the inappropriateness of the assessment content and format for the needs and abilities of some students. Another possible reason is the consequences attached to the accountability systems, particularly high stakes consequences. Allied to this requirement is the need for the development of guidelines for exclusion. The need for consistent guidelines for exclusion is as great as the need for the introduction of a common definition of disability. This is essential, given the lack of information on the status and characteristics of those students who are excluded (MCEETYA, 2002).

A final requirement is clarification on additional provisions for students with disabilities. Guidelines for accommodations and alternative assessment also vary significantly across jurisdictions. This raises questions about the validity of the outcome measures from students who have received these provisions.

Few would argue against the goal that schooling should be "socially just" that was endorsed at the Adelaide Declaration. Further, there is broad support for the goal that the outcomes from schooling for students with a disability should be free from discrimination. Unfortunately, there is a considerable gulf between these goals and educational practice, and in particular educational accountability, for students with a disability in Australia. The extent to which the likely introduction of education 
standards from the DDA may facilitate change in this area is, at the moment, unclear. However, without some leadership from the Commonwealth Government, and other jurisdictions, it is highly unlikely that the state and territory education jurisdictions will develop consistent guidelines to clarify the participation by students with a disability in national testing. 


\section{References}

Ahearn, E.M. (2000). Synthesis Brief. Students with disabilities in state assessments: The NCEO state reports. Eric Document Reproduction Service, No. ED445433.

Albrecht, S.F. \& Joles, C. (2003). Accountability and access to opportunity: Mutually exclusive tenets under a high-stakes testing mandate. Preventing School Failure, 47, 2, 86-91.

Australian Council for Educational Research (2002). Literacy and numeracy national assessment testing program 2002: Principal's handbook. Sydney: Author

Bechger, T.M, vanSchooten E., deGlopper, C. \& Hox, J.J.J. (1998). The validity of international surveys of reading literacy: the case of the IEA reading literacy study. Studies in Educational Evaluation, 24, 2, 99-125.

Booth, T. \& Ainscow, M. (1998). Introduction. In T. Booth and M. Ainscow (Eds.), From them to us: an international study of inclusion in education, (pp.1-20). NY: Routledge.

Boscardin, M.L. (1997). The impact of special education legislation on schooling: A United States perspective. In D. Mitchell \& J.Kugelmass (Eds.), The view finder: new models for re-forming special education, Volume 4, pp. 4-11, DISES: Reston, VA.

Brown, R.L. (1997). Legislation in Australian special education intent and effect: the impact on child, family and teacher. In D. Mitchell \& J.Kugelmass (Eds.), The view finder: new models for re-forming special education, Volume 4, pp. 4145. DISES: Reston, VA.

Carter, C., Gibbs, G., Gibson, R., Glogau, L. and Orpe, J. (2001). New Zealand National Certificate of Educational Achievement: Development progress in 2000-2001. Paper presented at the Annual conference of ACACA, July. Retrieved from the World Wide Web on June 6, 2003. www.boardofstudies.nsw.edu.au/manuals.pdf_doc/nzministry.pdf

Consortium on Inclusive Schooling Practices (1998). Including students with disabilities in accountability systems. Pittsburgh: Author.

Council of Ministers of Education, Canada. (2002a). School Achievement Indicators Program (SAIP). An insert to the SAIP report on mathematics III assessment, 2001: highlights from the report. Retrieved from the World Wide Web on June 6, 2003.www.cmec.ca/saip/math2001/public/highlights.en.pdf

Council of Ministers of Education, Canada. (2002b). The School Achievement Indicators Program (SAIP). Writing assessment III. Information for parents and students. Retrieved from the World Wide Web on June 6, 2003. www.cmed.ca/saip/2002we/hdbk.parents.en.pdf 
Dempsey, I., Foreman, P., \& Jenkinson, J. (2002). Educational enrolment of students with a disability in New South Wales and Victoria. International Journal of Disability, Development and Education, 49, 1, 31-46.

Department of Education, Science and Training (2002a). National Goals and Adelaide Declaration. Retrieved from the World Wide Web on June 6, 2003. www.dest.gov.au/schools

Department of Education, Science and Training. (2002b). The Adelaide Declaration on National goals for schooling in the twenty-first century. Retrieved from the World Wide Web on June 6, 2003.

www.dest.gov.au/schools/adelaide/index.htm

Department of Education, Science and Training. (2002c). Literacy and numeracy. Retrieved from the World Wide Web on June 6, 2003.

http://www.dest.gov.au/schools/literacy\&numeracy/index.htm

Department of Education, Science and Training (2002d). Inquiry into the education of students with disabilities. Submission to the senate employment, workplace relations and education references committee. Retrieved from the World Wide Web on June 6, 2003.

http://www.aph.gov.au/senate/committee/eet_ctte/reports/index.htm

Department of Education Training and Employment, South Australia (2002). South Australian Curriculum Standards and Accountability Framework: an Overview. Retrieved from the World Wide Web on June 6, 2003. http://www.sacsa.sa.edu.au/ATT/\%7BA7DCD84C-792C-4BO3-9FBC35CV6D6E01C\%7D/SACSA.OVERVIEW.pdf

Dore, R., Wagner, S. \& Brunet, J.P. (1998). School integration of children with a disability in provinces and territories in Canada. Retrieved from the World Wide Web on June 6, 2003. www.cmec.ca/stats/pcera/compapaer/98_44en.pdf

Dorn, S. (1998). The political legacy of school accountability systems. Education Policy Analysis Archives, 6, 1, 1-36.

Dyson, A. (1997). Dilemmas, contradictions and democracy: models in the governance of special needs education in England and Wales. In D. Mitchell \& J.Kugelmass (Eds.), The View Finder: New models for re-forming special education, Volume 4, pp 12-19. DISES: Reston, VA.

Elliot, J.L., Hyeonsook, Thurlow \& Ysseldyke (1995). A perspective on education and assessment in other nations: Where are students with disabilities? Washington DC: National Centre on Educational Outcomes.

Elliot, J.L. \& Thurlow, M.L. (1997). Opening the door to educational reform: understanding educational assessment and accountability. Minneapolis: National Center on Educational Outcomes. 
Falk, B. (2002). Standards-based reforms: Problems and possibilities. Phi Delta Kappan, 83, 8. 612-620.

Firestone, W.A. \& Mayrowetz, D. (2000). Rethinking "High Stakes”: lessons from the United States and England and Wales. Teachers College Record, 102, 4, 724749.

Ford, A., Davern, L. \& Schnorr, R. (2001). Learners with significant disabilities: curricular relevance in an era of standards-based reform. Remedial and Special Education, 22, 4, 214-222.

Foreman, P. (2001). Integration and inclusion in action. Sydney: Harcourt.

Forlin, C \& Forlin, P. (1998). Discussion paper: Outcomes for students with special educational needs. Retrieved from the World Wide Web on January 2, 2003. http://education.qld.gov.au/tal/liu/support/articles/gen.art/981209dg.pdf

Giacobbe, A.C., Livers, A.F., Thayer-Smith, R. \& Walther-Thomas, C. (2001). Raising the academic standards bar. Journal of Disability Policy Studies, 12, 1, 10-17.

Hahn, H. \& Hegamin, A.P. (2001). Assessing scientific measures of disability. Journal of Disability Policy Studies, 12, 2, 114-121.

Hoff, D.J. (2001). 'New standards' leaves legacy of unmet goals. Education Week, 20, 26-33.

Jones, R.W. (1999). The Third International Mathematics and Science Study: anatomy of this international comparative study in science education. Australian Science Teachers’ Journal, 45, 2, 27-37.

Kalyanpur, M \& Harry, B. (1999). Culture in special education: building reciprocal family-professional relationships. Baltimore: Paul H Brookes.

Kearns, J.F., Kleinert, J.L. \& Kennedy, S. (1999). We need not exclude anyone. Educational Leadership, 56, 6, 33-38.

Kleinert, H.L., Haig, J., Kearns, J.F. \& Kennedy, S. (2000). Alternate assessments: lessons learned and roads to be taken. Exceptional Children, 67, 1, 51-66.

Labon, D. (1999). Inclusive education at work: students with disabilities in mainstream schools. Paris: Organisation for Economic Cooperation and Development.

Lingard, T. (2000). Is the National Literacy Strategy raising the achievement of lower attainers? British Journal of Special Education, 27, 3, 117-123.

Lokan, J. (1997). Overview of Developments with the National Statement and Profiles to 1993. In J. Lokan (Ed.), Describing learning: implementation of 
curriculum profiles in Australian schools 1986-1996. ACER Research Monograph No50. Melbourne: ACER.

Lupart, J.L. (2000). Students with exceptional learning needs: at-risk, utmost. Retrieved from the World Wide Web on June 6, 2003. http://www.cmec.ca/stats/pcera/symposium2000/lupart.en.pdf

Massanari, C.B. (2002). Alternate assessment: questions and answers. Mountain Plains Regional Resource Centre. Retrieved from the World Wide Web on June 6, 2003. www.ideapractices.org/qanda/pdf/AlternativeAssessment.pdf

Matlock, L., Fielder, K. \& Walsh, D. (2001). Building the foundation for standardsbased instruction for all students. Teaching Exceptional Children, 33, 5, 6872.

McDermott, T.K. \& McDermott, D.F. (2002). High-stakes testing for students with special needs. Phi Delta Kappan, 83, 7, 504-5, 544.

McLaughlin, M.J., Nolet, V., Rhim, L.M. \& Henderson, K. (1999). Integrating standards including all students. Teaching Exceptional Children, 31, 3, 61-71.

McNeil, L.M. (2000). Creating new inequalities: contradictions of reform. Phi Delta Kappan, 81, 9, 729-734.

Ministerial Council of Education, Employment, Training and Youth Affairs. (2002). National report on schooling in Australia: Preliminary paper. National benchmark results: Reading and Numeracy: Years 3 and 5. Retrieved from the World Wide Web on June 6, 2003. http://www.curriculum.edu.au/mctyapdf/2000_benchmardks.pdf

Mitchell, D. (1997). Special education legislation and policies in the context of education reforms: the New Zealand model. In D. Mitchell \& J.Kugelmass (Eds.) The View Finder: New models for re-forming special education, Volume 4, pp 20-25. DISES: Reston, VA.

Mitchell, D \& Kugelmass, J. (1997). Introduction. In D. Mitchell \& J.Kugelmass (Ed.s) The View Finder: New models for re-forming special education, Volume 4, pp 1-3. DISES: Reston, VA.

National Centre for Educational Statistics (2000). Mathematics and Science in Eighth Grade: findings from the Third International Mathematics and Science Study. http://nces.ed.gov/pubsearch/pubsinfo.aop?puid=2000014

NSW Board of Studies (2002). ACE Assessment, Certification and Examination Manual. Retrieved from the World Wide Web on December 12, 2002. http://www.boardofstudies.nsw.edu.au/manual/pdf.doc/ace_manual_02.pdf

Nolet, V. \& McLaughlin, M.J. (2000). Accessing the general curriculum: including students with disabilities in standards-based reform. San Francisco: Thousand Oaks. 
O'Leary, M. (2000). The Effects of age-based and grade-based sampling on the relative standing of countries in international comparative studies of student achievement. Paper presented as the Annual Meeting of the American Educational Research Association. New Orleans: April 24-28.

Organisation for Economic Cooperation and Development (2002). Participation Rates. Retrieved from the World Wide Web on June 6, 2003. http://www.pisa.oecd.org

Pascoe, S. (2001). Generic versus content-driven assessment. Paper presented at the 2001 annual conference for the Australian Curriculum, Assessment and Certification Authorities. Retrieved from the World Wide Web on December 16, 2002. http://www.boardofstudies.nsw.edu.au/manuals.pdf.doc/pascoe.pdf

Popham, W.J. (1999). Why standardised tests don't measure educational quality. Educational Leadership, 56, 6, 8-15.

Quenemoen, R.F., Lehr, C.A., Thurlow, M.L. \& Massanari, C.B. (2001). Students with disabilities in standards-based assessment and accountability systems: emerging issues, strategies and recommendations. NCEO Synthesis Report 37. Washington: National Centre on Educational Outcomes.

Roach, V., Salisbury, C. \& McGregor, G. (2002). Applications of a policy framework to evaluate and promote large-scale change. Exceptional Children, 68, 4, 451464.

Sirotnik, K.A. \& Kimball, K. (1999). Standards for standards-based accountability systems. Phi Delta Kappan, 81, 3, 209-214.

Skrtic, T.M. (1995). The functionalist view of special education and disability: deconstructing the conventional knowledge tradition. In T.M. Skrtic (Ed.) Disability and Democracy: Reconstructing (Special) Education for Postmodernity, pp65-103. New York: Teachers College Press.

Smith, W.J. \& Foster, W.F. (1997). Legal rights for students with disabilities: indicators of legislative performance in Canada. In D. Mitchell \& J.Kugelmass (Eds.) The View Finder: New models for re-forming special education, Volume 4, pp 26-33. DISES: Reston, VA.

Stakes, R. \& Hornby, G. (2000). Meeting special needs in mainstream schools: a practical guide for teachers, $\left(2^{\text {nd }}\right.$ Ed.). London: David Fulton.

Thomas, M.D. \& Bainbridge, W.L. (2001). All children can learn: facts and fallacies. Phi Delta Kappan, 82, 9, 660-662.

Thurlow, M. \& Bolt, S. (2001). Empirical support for accommodations most often allowed in state policy (Synthesis Report 41). Minneapolis, MN: University of Minnesota, National Centre on Educational Outcomes. Retrieved from the 
World Wide Web on December 16, 2002.

http://education.umn.edu/NCEO/OnlinPubs/Synthesis41.html

Thurlow, M.L., Nelson, R.J., Teelucksingh, E. \& Ysseldyke, J.E. (2000). Where's Waldo? A third search for students with disabilities in State accountability reports. Technical Report 25. Washington DC: University of Minnesota.

Vanderwood, M., McGrew, K.S. \& Ysseldyke, J.E. (1998). Why we can’t say much about students with disabilities during educational reform. Exceptional Children, 64, 3, 359-370.

Webster, B.J \& Fisher, D.L (2000). Accounting for variation in Science and Maths achievements: a multi-level analysis of Australian data on the Third International Mathematics and Science Study. School Effectiveness and School Improvement, 11, 3, 339-360.

Wedell, K. (1997). The national curriculum, educational standards and the local management of English schools. In OECD (Ed.), Implementing Inclusive Education, pp 154-162. Washington, DC: OECD.

Winstanley, C. (2001). Reporting and moderation processes for the New Zealand National Certificate of Educational Achievement (NCEA). Paper presented at the Annual ACACA conference, July 2001. Retrieved from the World Wide Web on December 12, 2002.

www.boardofstudies.nsw.edu.au/manuals.pdf_doc/winstanley.pdf

Yackulic, R.A. \& Noonan, B.W. (1998). Measurement of the full scope of learning. Retrieved from the World Wide Web on June 6, 2003. www.cmec.ca/stats/pcera/compaper/98-28en.pdf

Ysseldyke, J. E. \& Nelson, R.J. (1998). Enhancing communication: Desirable characteristics for state and district educational accountability reports (Synthesis Report No. 30). Minneapolis, MN: University of Minnesota, National Centre on Educational Outcomes. Retrieved from the World Wide Web on December 12, 2002.

http://education.umn.edu/NCEO/OnlinePubs/Synthesis30.html

Zammit, S.A., Meiers, M \& Frigo, T. (1999). Assessment and reporting of student achievement for students with specific educational needs against literacy and numeracy benchmarks. Melbourne: ACER. 